\title{
Population Screening for Cancer Family Syndromes in the West Pomeranian Region of Poland
}

\author{
Jacek Gronwald', Andrzej Raczyński', Mariusz Tarhoni ${ }^{2}$, Mirosław Blachowski' ${ }^{2}$ Tomasz Huzarski', Tomasz Byrski', \\ Aleksandra Tołoczko-Grabarek', Tadeusz Dębniak', Cezary Cybulski', Jowita Huzarska', Oleg Oszurek', Jan Lubiński' \\ International Hereditary Cancer Center, Pomeranian Medical University, Szczecin, Poland; 2West Pomeranian Regional Health Foundation, Szczecin, Poland
}

Key words: population screening, cancer family syndromes, familial doctors

Corresponding author: Jacek Gronwald, International Hereditary Cancer Center, Pomeranian Medical Univeristy, ul. Połabska 4,70-115 Szczecin, Poland; e-mail: igron@uoo.univ.szczecin.pl

Submitted: 19 December 2005

Accepted: 10 January 2006

The largest worldwide population screening for cancer family syndromes was initiated in January 2001 in the West Pomeranian Region of Poland with $1.7 \mathrm{~m}$ inhabitants. In the first step in the period January 2001 - May 2002 family doctors and nurses collected questionnaires asking about cancer family history among 1 st and 2 nd degree relatives from 1,258,401 of $1.5 \mathrm{~m}$ individuals (87\%) who were insured in the West Pomeranian Regional Health Foundation. Up to now about $1.15 \mathrm{~m}$ questionnaires have been evaluated by geneticists/oncologists. According to questionnaire data around $2 \%$ of families fulfilled criteria to be suspected for cancer family syndrome. Family members (usually 1-2 representatives per family) from suspected families were invited for detailed examination. After pedigree and clinical examination as well as DNA/RNA analyses, high genetic predisposition to neoplasms was diagnosed in 10,525 families. Diagnosis of the following syndromes was established definitively or with high probability:

1. Hereditary breast/ovarian cancer syndrome - 4121 families including 438 families with diagnosed BRCA1/2 mutation.

2. Familial syndromes of colorectal cancer:

a) HNPCC - 568 families including 63 families with diagnosed $\mathrm{MSH} 2 / \mathrm{MLH} 1$ mutation,

b) FAP - 22 families,

c) Late onset colorectal cancer aggregations - 459 families.
3. Other hereditary organ specific syndromes:
a) hereditary stomach cancer - 1250 families,
b) hereditary renal cancer - 565 families,
c) hereditary laryngeal cancer - 206 families,
d) hereditary prostate cancer - 170 families,
e) NFI - 66 families,
f) $\mathrm{VHL}-36$ families,
g) Retinoblastoma - 4 families,
h) Peutz Jeghers syndrome -3 families,
i) juvenile polyposis - 2 families.

4. Organ-specific familial aggregations:
a) familial lung cancer - 242 families,
b) familial leukaemia/lymphoma - 77 families,
c) familial liver cancer - 68 families,
d) familial cervical cancer - 30 families,
e) familial pancreatic cancer - 73 families,
f) familial melanoma - 44 families,
g) familial bladder - 19 families.

5. Unspecified cancer family aggregations - 3319 families.

Appropriate management has been introduced in all identified families with high predisposition to malignancies. 